\title{
Leadership Behavior and Employees Job Satisfaction: Working for Organizational Success
}

\author{
Shoukat Ali Mahar ${ }^{1}$, Nazar Hussain ${ }^{2}$, Ghulam Saqib ${ }^{3}$, Shah Muhammad Farooq ${ }^{4}$, Abdul Rehman \\ ${ }^{1,2}$ Department of Public Administration, Shah Abdul Latif University, Khairpur, Pakistan \\ ${ }^{3}$ Institute of English Language and Literature, University of Sindh Jamshoro, Pakistan \\ ${ }^{4}$ Department of Sociology, Shah Abdul Latif University, Khairpur, Pakistan \\ ${ }^{5}$ Department of Public Administration, Shah Abdul Latif University, Khairpur, Pakistan
}

\section{ABSTRACT}

Purpose: This study was designed to understand the relationship between leadership behaviors and employees job satisfaction at microfinance banks. It also shows how and to what extent these leadership styles affect job satisfaction.

Design: The questionnaire was used to collect data from 290 employees of the Microfinance Bank. The convenient sampling was used to gather data. The literature indicates that there is a correlation among all proposed variables. Researcher applied regression and Pearson correlation to get the results.

Findings: The results show that participative behavior and supportive leadership behaviors have significant and positive effect on employees' job satisfaction in Micro Finance Institutions of Khairpur.

Value: no doubt this study found that participative behavior has significant relationship with employees' job satisfaction and in increase the work productivity, it develops the sense of equivalence in work, it also encourages the essence of employees' role in decision making, in this regard employees like to help organisation in organizational success

Practical implications: Results of this Research mean that participatory leaders can participate in role modeling by providing employees with interesting workplace activities to increase job satisfaction.

Recommendation: The population used for the survey was limited to 14 branches of MFBs in the Khairpur area.. Therefore, this study can be extended to a variety of other commercial and noncommercial organizations. This helps researchers to fully understand leadership style and its impact on job satisfaction.

Limitation: This study is limited to certain MFBs of Khairpur district.

\section{Introduction}

Employees play crucial role in organizations to meet the personal and organizational needs. Whereas, organizations have need of someone who can systematically meet their personal needs and organizational goals it is possible if leaders are contributes perfectly (Ratnasari et al, 2020). These people have an extraordinary quality and ability to manage and guide employees because they can achieve the highest level of results to meet the needs of individuals and organizations (Xue et al, 2020). An enterprise needs someone who can manage, control, and direct the work to meet the needs of its employees while at the same time showing a satisfactory attitude toward higher work (Luu et al, 2020). The main role of a business leader is to choose the most effective way to achieve personal and career goals. Provide coordination among employees and share 
information needed to maintain current and future forecasts. Ensure fairness and professionalism within the organization to increase job satisfaction and reduce the supply of skilled workers or jobs (Ratnasari et al, 2020)

Larry (2002) proved that most organizational functions are usually considered as an organizational leadership style. It covers a wide range of managerial and administrative issues, including the degree to which the organization sets strategic goals and the extent to which they communicate and participate through each employee. (Riana, I. G. 2015) conducted a study on micro-financial institutions to understand how leadership behavior affects employee job satisfaction. The success of the organization depends on the ability to achieve organizational goals and objectives and depends on the behavior and attitude of leaders. By adopting inappropriate leadership styles, leaders cannot create job satisfaction, loyalty and competence. Dissatisfaction with a higher employment rate reduces productivity and leads to employee turnover and lower productivity.

\section{Research objectives}

- To measure the effect of directive leadership behavior in in creating employees job satisfaction in micro finance institution of Khairpur

- To find out contribution of participative leadership behavior in creating employees job satisfaction in micro finance institution of Khairpur

- To understand the influence of supportive leadership behavior in creating employees job satisfaction in micro finance institution of Khairpur.

\section{Research Model}

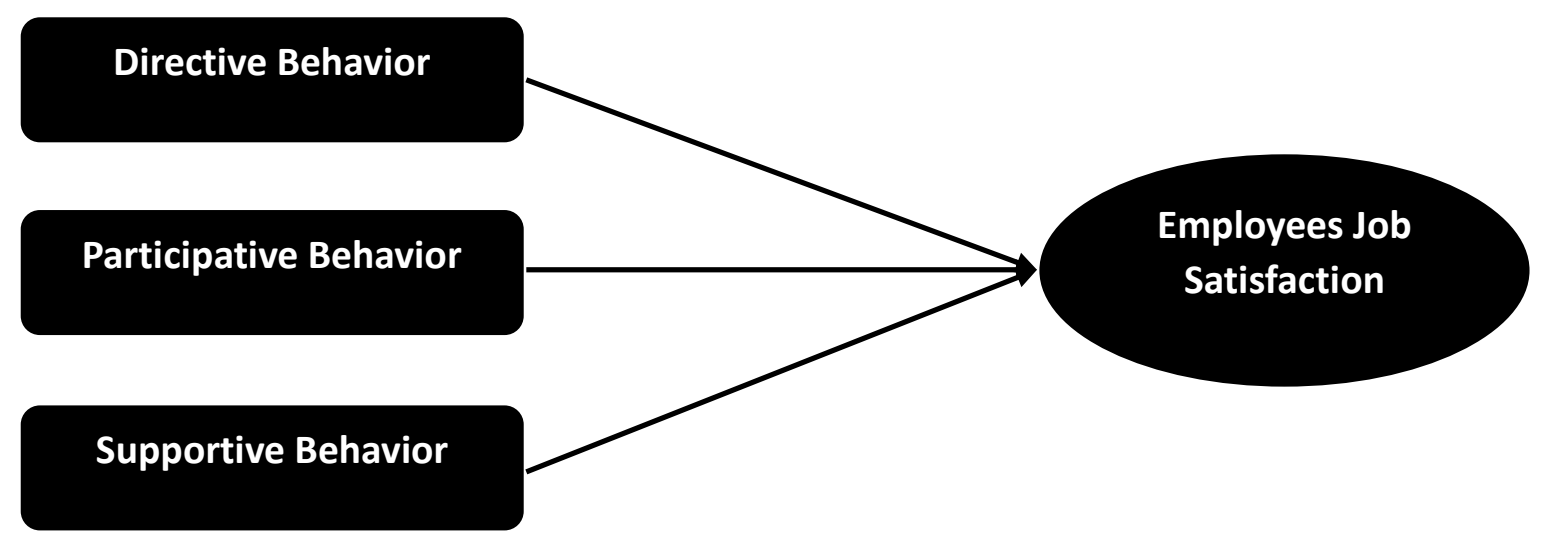

\section{Hypotheses}

H1 There is positive and significant effect of directive leadership behavior in in creating employees job satisfaction in micro finance institution of Khairpur

$\mathrm{H} 2$ There is positive and significant contribution of participative leadership

www.psychologyandeducation.net behavior in creating employees job satisfaction in micro finance institution of Khairpur

H3 There is positive and significant influence of supportive leadership behavior in creating employees job satisfaction in micro finance institution of Khairpur. 


\section{Literature review}

Effective leadership and employee well-being are two important aspects to organizational success. A competent leader provides goals for the organization and guides employees to achieve the expected goals of the organization. Likewise, more employees who are satisfied with their job are expected to pursue excellent work and organizational goals. Organizations that do not create a culture of high job satisfaction may not be able to stop their employees from doing business and recruit employees to use the required skills. In this regard, research has been conducted on the importance of leadership actions in creating job satisfaction.

A leader who supports innovation and creative identity and is ready to attract and satisfy the maximum subordinates is important for any organisation and it is responsibility of every leader to consider the loyalty of every employee for organizational success (Naveed, 2011). Human resources are considered to be one of the fundamental parts of every organization supported by internal and external factors. One of the key projects to improve human resources is job satisfaction (Mahar, 2019) and it is possible in organizations through effective leadership behavior .The existence of job satisfaction can increase the amount of personal effort, communication, employee competencies, employees, and their work toward a full organization Selznick, P. (2011). Many issues surrounding effective factors encourage satisfaction and change dissatisfaction, such as unfair leadership styles in public education organizations. In addition, it seems that educational institutions with flying in public education institutions, some managers are unintentional.

In fact, previous researches the external factors are also directly related to the satisfaction of employees in organizational environmental. Therefore, satisfaction is linked to its influence on the spirit of employees and changing their attitudes related to work (Saxena, 2012).

\section{Directive Behavior (DB)}

Directive leaders have absolute power and influenced by followers and requirements. Directive leaders have always been cherished by the community and culture, and they naturally accept a hierarchical structure in the leadership to legitimize the unequal relationship between subordinates and superiors. These communities often require the authorities to abide by the assigned duties and tend to be authoritarian and produce authoritarian leaders. Under the rule of absolute leaders, authoritarian leadership is from the lowest to the most popular, probably because job satisfaction is relatively low (Kate, 2013). Directed leadership Invite subordinates to indicate what they need and give specific instructions. Subordinates are relied upon to pursue the standards and guidelines (Mullins, 2005). Instructing administration is depicted as tyrant, work-situated, rousing and controlling (bass 1981). While it can adequately pass on a reasonable and succinct way to deal with the association's vital objectives, Directive Leadership is an amazing change. Because of the official idea of the order chiefs, in the event that they are prohibited from the basic leadership process, there might be fewer chances to receive the board's vision or qualities. Bass (1981) refers to various investigations that demonstrate that the consequence of showing administration is less acknowledgment of the executives' choices than an increasingly participatory initiative style. Disappointment of workers in the board esteems can be a specific issue for administration associations since fringe individuals regularly need to settle on choices and redo administrations (Hartline, Maxim and McKee 2000). 


\section{Participative Behavior (PB)}

Coordinators and leaders of the consultations decided to invite organizers to review their comments and suggestions (Mullins, 2005). Participant consent involves guidance, empowerment and participation (Bass 1981). The results are understood as employee guidance or leadership behavior and the involvement of their managers who are more committed to the organization and are satisfied with its work and high performance (Mahar, 2019). This can increase the power of representation and respect for the board of directors due to the careful consideration of member management.

Representatives who work for the work under the initiative of the gathering, they show more cooperation, responsibility and devotion than workers who have a chief head (bass, 1981). Hence, workers who are permitted to take an interest in the basic leadership procedure might be progressively dedicated to these choices. Since cutting edge workers in the financial business will in general find out about their needs than directors, representatives have direct contact with clients. In this way, the board ought to enable representatives to take an interest in the basic leadership process. Support, representative responsibility, initiative potential, expanded commitment and reliability are an alluring duty that supervisors should make to the individuals who need to advance their own administration quality.

\section{Supportive Behavior (SB)}

Supportive leadership is a leadership style in which managers can not only assign tasks and achieve results, but also help employees before they complete work. An important aspect of supportive leadership is that the manager will work with the employee until he or she is proficient or skilled and will be able to complete the task with minimal supervision in the future.

\section{Leadership Supportive and Traditional way of dealing with Employees}
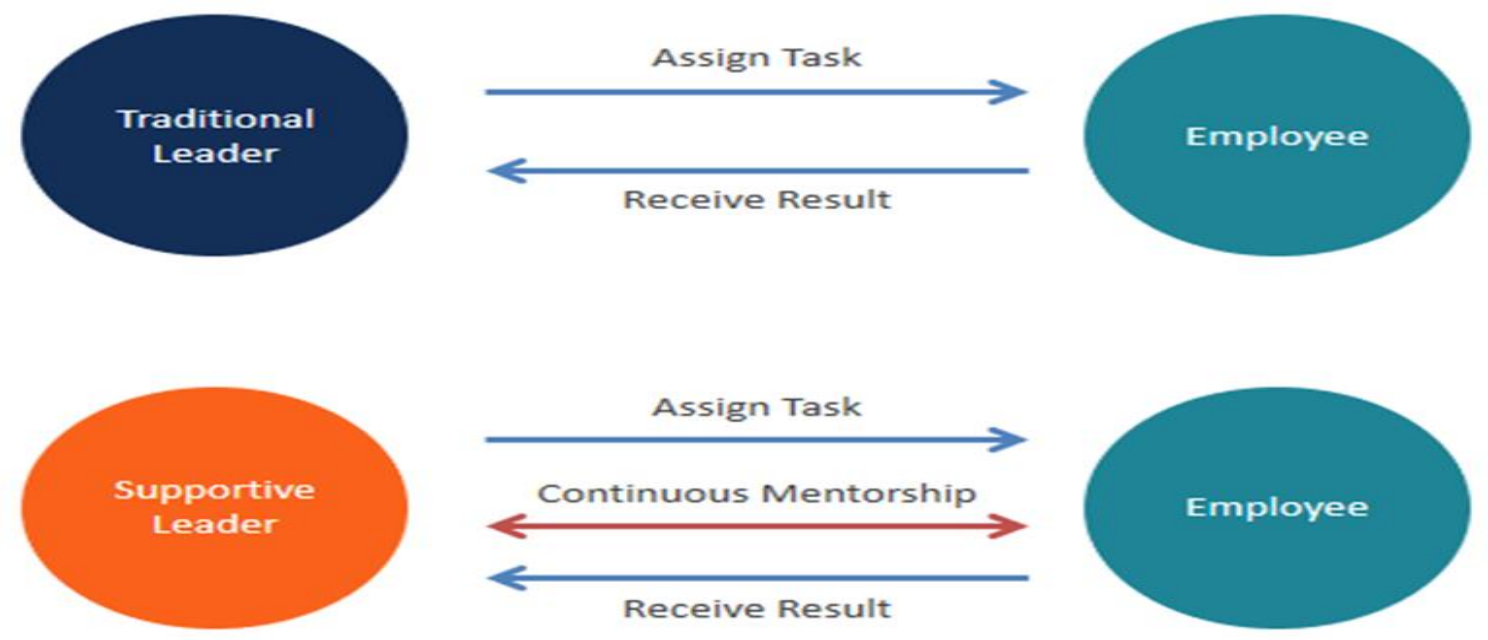

The supportive leadership style hopes to establish relationships with subordinates. This is a different approach to work-oriented style, with a focus on fulfilling mandates and goals. Although the public-oriented leadership style is considered an incentive style, it is accompanied by professionals and opponents. Most leaders add wind to the best results 


\section{Job Satisfaction (JS)}

Job satisfaction is a combination of all aspects of the job, such as the nature of the job, the level of compensation, the opportunity for promotion, and the employee's feelings of satisfaction with colleagues. In this case, emotions mean pleasant or positive emotional conditions resulting from the assessment of work experience. Job satisfaction is associated with increased productivity and organizational commitment, reduced absenteeism and turnover, and ultimately, organizational efficiency increases. According to Wright and Davis (2003), the benefits employees receive from the organization affect the effort, skills, creativity, and productivity they are willing to pay. It has been found that reduced job satisfaction is drowsy and organizational commitment is reduced (Moser, 1997). Lack of job satisfaction has become a predictor of smoking cessation (Hermann, 2005). Sometimes workers can be left in the private sector and vice versa. Sometimes, sports take place from one occupation to another. Poor service conditions and payment of arrears are the reasons for reducing unemployment and job satisfaction.

\section{Descriptive Analysis Results}

\begin{tabular}{llll}
\hline Name & Option & Frequency & Total percentage \\
\hline gender & Male & 140 & $100 \%$ \\
Age & Female & 18 & \\
& Below 30 years & 92 & $100 \%$ \\
Education & Above 30 years & 66 & $100 \%$ \\
& Bachelor & 46 & \\
\multirow{3}{*}{ Experience } & Master & 108 & \multirow{2}{*}{$100 \%$} \\
& Mphil /ms & 4 & \\
& Less than 5 years & 84 & \\
& 5 to 10 years & 54 & $100 \%$ \\
Income & 10 to 15 & 15 & \\
& More than 15 years & 5 & \\
& Rs 10k-20k & 33 & \\
& Rs 20k-30k & 52 & \\
& Rs 30k-40k & 46 & \\
& More than 40k & 27 & \\
& &
\end{tabular}

Age: This table represents the age of different respondents who were working in Micro Finance Banks operating in Khairpur, in these employees $58.20 \%$ had age less than 30 years and $41.80 \%$ were possessing age more than 30 years.

Gender: Among 158 employees, working in Micro Finance Banks of Khairpur $88.60 \%$, were male and $11.40 \%$, were female whereas, total number of employees were 290 and data was personally collected from branches to ensure accuracy of results. As shown in above mentioned table.

Education: Above table represents the education level of respondent where 46 were bachelor holder 108 were master holder and 4 were postgraduates equal to M.Phil. Namely $29.10 \%$ were 14 -year 
education $68.40 \%$ were 16-year education and $2.50 \%$ had 18-year education. Below this table is given that indicates all respondents in graphical representation.

Experience: Above table describes the detail of respondents experience among 158 respondents $53.2 \%$ had experience of less than 5 years, $34.20 \%$ had experience of 5 to 10 years, $9.50 \%$ had experience in between 10 to 15 years and $3.50 \%$ had more than 15 years' experience

Income: Above table is about the income level of respondents so it was asked from them to show their income where 33 respondents had income of between ten thousands to twenty thousand whereas, 52 had income of twenty thousands to thirty thousands, further it is clear from table results that 46 employees had monthly income between thirty thousands to forty thousands and 27 employees had income of more than 40 thousands in whole total number of respondents in this research were 158 employees.

\subsection{Reliability Analysis}

Reliability describes the consistency of responses namely consistency of data so for reliability analysis Cronbach's alpha techniques was used it follows criteria if is equivalent to .6, it will be treated poor, if it is .7, it will be considered average , .8 is good and .9 will be considered excellent . So, in this regard total reliability is .893 that is most appropriate. Further let researcher to clear you the reliability of each question is checked, and all have good reliability.

\section{Table \# 4: $\quad$ Reliability and KMO Results}

\begin{tabular}{lll}
\hline Name of Variable & Reliability & KMO \\
\hline Direct behavior & .860 & .813 \\
Participative behavior & .907 & .834 \\
Supportive behavior & .862 & .726 \\
Job Satisfaction & .852 & .667 \\
Over all Reliability & .893 & .674 \\
\hline
\end{tabular}

Again, in above table reliability of each variable is given and all variables meet with the research criteria reliability means all variables have good reliability. Further above table shows the KMO value of each variable that indicates the accuracy of each variables sampling size, and it follows criteria if is .6 or more than .6 it will be considered accurate, so all variables have KMO vale is more than .6 namely. Directive behavior has KMO vale is .813 , participative .834 , supportive behavior .726 and dependent variable employees job satisfaction is .667 whereas total $\mathrm{KMO}$ of questionnaire is .674 .

\subsection{Exploratory Factor Analysis.}

This technique is used to ensure what questions are appropriately working in research to acquire proper results of data in this connection it is said when questionnaire is modified, or self-made this technique will be applied and same is done here. 
Article Received: 16th October, 2020; Article Revised: 30th December, 2020; Article Accepted: 08th January, 2021

Table \# 6: $\quad$ Rotated Component Matrix Results

\begin{tabular}{|c|c|c|c|c|}
\hline \multicolumn{5}{|c|}{ Rotated Component Matrix ${ }^{\mathrm{a}}$} \\
\hline & Component & & & \\
\hline & 1 & 2 & 3 & 4 \\
\hline DL6 & .829 & & & \\
\hline JS9 & .828 & & & \\
\hline JS13 & .825 & & & \\
\hline DL4 & .821 & & & \\
\hline DL3 & .801 & & & \\
\hline JS12 & .787 & & & \\
\hline JS10 & .704 & & & \\
\hline DL1 & .682 & & & \\
\hline DL5 & .662 & & & \\
\hline SL3 & & .933 & & \\
\hline SL2 & & .883 & & \\
\hline SL4 & & .862 & & \\
\hline PL7 & & .856 & & \\
\hline SL1 & & .832 & & \\
\hline SL5 & & .742 & & \\
\hline PL4 & & & .928 & \\
\hline PL1 & & & .919 & \\
\hline PL5 & & & .896 & \\
\hline PL6 & & & .874 & \\
\hline PL2 & & & .827 & \\
\hline PL3 & & & .690 & \\
\hline JS1 & & & & .865 \\
\hline JS2 & & & & .853 \\
\hline SL8 & & & & .832 \\
\hline SL7 & & & & .769 \\
\hline SL6 & & & & .758 \\
\hline JS3 & & & & .725 \\
\hline
\end{tabular}

Extraction Method: Principal Component Analysis.

Rotation Method: Varimax with Kaiser Normalization.

a. Rotation converged in 6 iterations.

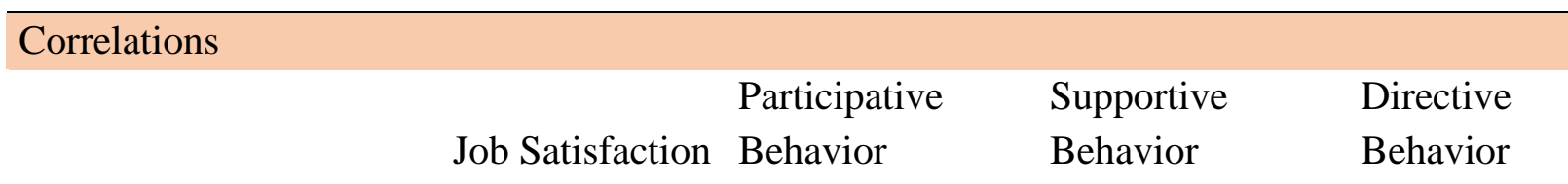

Job Satisfaction 1

www.psychologyandeducation.net 
Participative Behavior

Supportive Behavior

Directive Behavior
.336

$\begin{array}{lc}.734^{* *} & 1 \\ .513^{* *} & .452^{* *} \\ .336^{* *} & .253^{* *}\end{array}$

.253

**. Correlation is significant at the 0.01 level (2-tailed). N:158

In the correlation table, match rows to columns between two consecutive variables. Pearson correlation is an actual correlation value that represents magnitude and direction Sig. (Both sides) is the interpreted $\mathrm{p}$-value and $\mathrm{N}$ is the number of observations involved. If the $\mathrm{p}$ value is less than 0.05 , researchers indicate that there is a statistically significant binary association between two consecutive variables. When $\mathrm{p}$-values exceed 0.05 , researchers have shown that there is no statistically significant association between two consecutive variables. Higher $\mathrm{R}$ coefficients indicate stronger relationships between variables. Smaller $r$ coefficients indicate weaker relationships. Positive correlations represent relationships that follow the same trajectory. As one value increases, the other value also increases. In addition, as one value decreases, the other value also decreases. Negative correlations represent relationships that propagate in different directions.
As one value increases, the other decreases. Also, as one value decreases, the other value also increases. So here participative behavior is strongly correlated with job satisfaction and supportive is moderately correlated with job satisfaction and directive behavior is weakly correlated with employees' job satisfaction.

\section{Regression Analysis}

This portion is comprised of three table no. 1 is model summary it indicates either independent variables are contributing in this research or not and all these variables are showing the fitness of model so here Directive Behavior, Participative Behavior and Supportive Behavior are contributing $58.90 \%$ in predicting job satisfaction and it can be seen in adjusted $\mathrm{R}^{2}$. might be remaining $\%$ can be observed through others variables used by future scholars.

\section{Table \# 8: $\quad$ Model Summary Results}

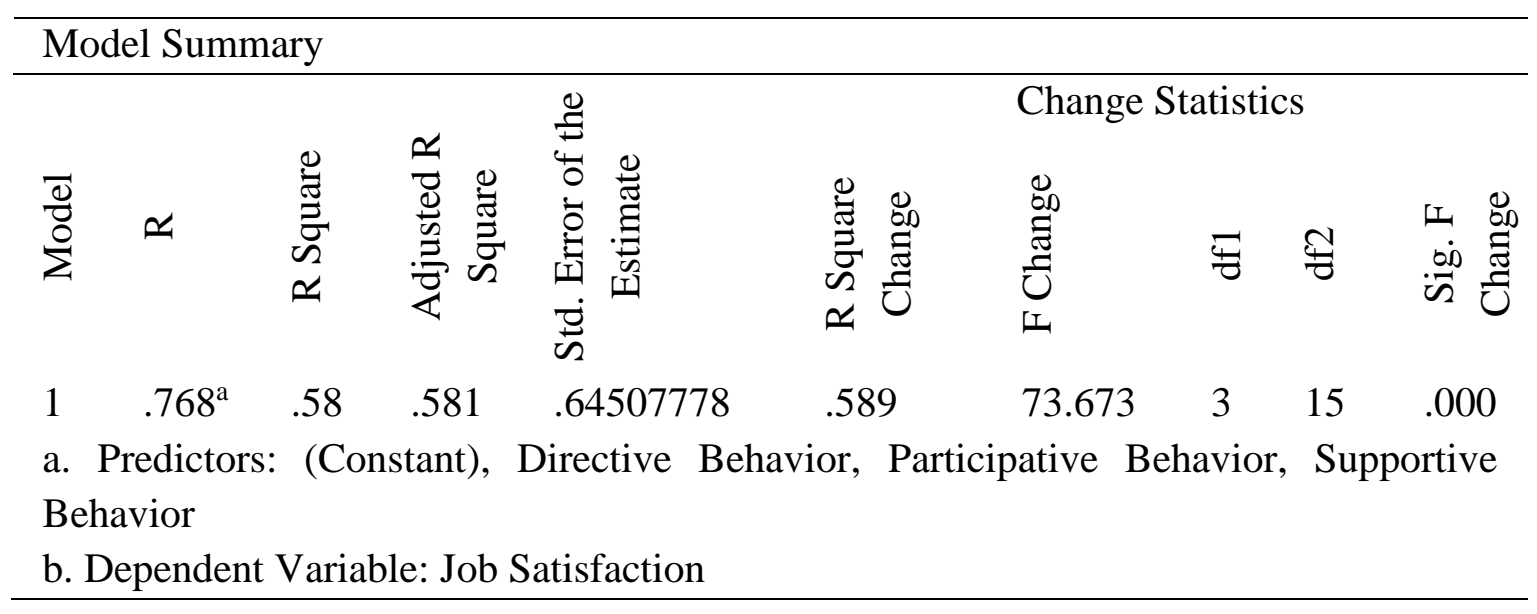

This is called analysis of variance it shows either independent variables are going to predict

www.psychologyandeducation.net dependent variables or not so here Directive Behavior, Participative Behavior and Supportive 
Article Received: 16th October, 2020; Article Revised: 30th December, 2020; Article Accepted: 08th January, 2021

Behavior are predicting significantly to job column having value of .000 satisfaction as shown in below table in sig.

\begin{tabular}{llllllll}
\hline & \multicolumn{5}{c}{ ANOVA $^{\mathrm{a}}$} \\
\hline Model & & Sum & of & df & Mean & F & Sig. \\
& & Squares & & & Square & & \\
1 & Regression & 91.971 & 3 & 30.657 & 73.673 & $.000^{\mathrm{b}}$ \\
& Residual & 64.083 & 154 & .416 & & \\
& Total & 156.055 & 157 & & &
\end{tabular}

a. Dependent Variable: Job Satisfaction

b. Predictors: (Constant), Directive Behavior, Participative Behavior, Supportive Behavior

\section{Multiple Regression Results}

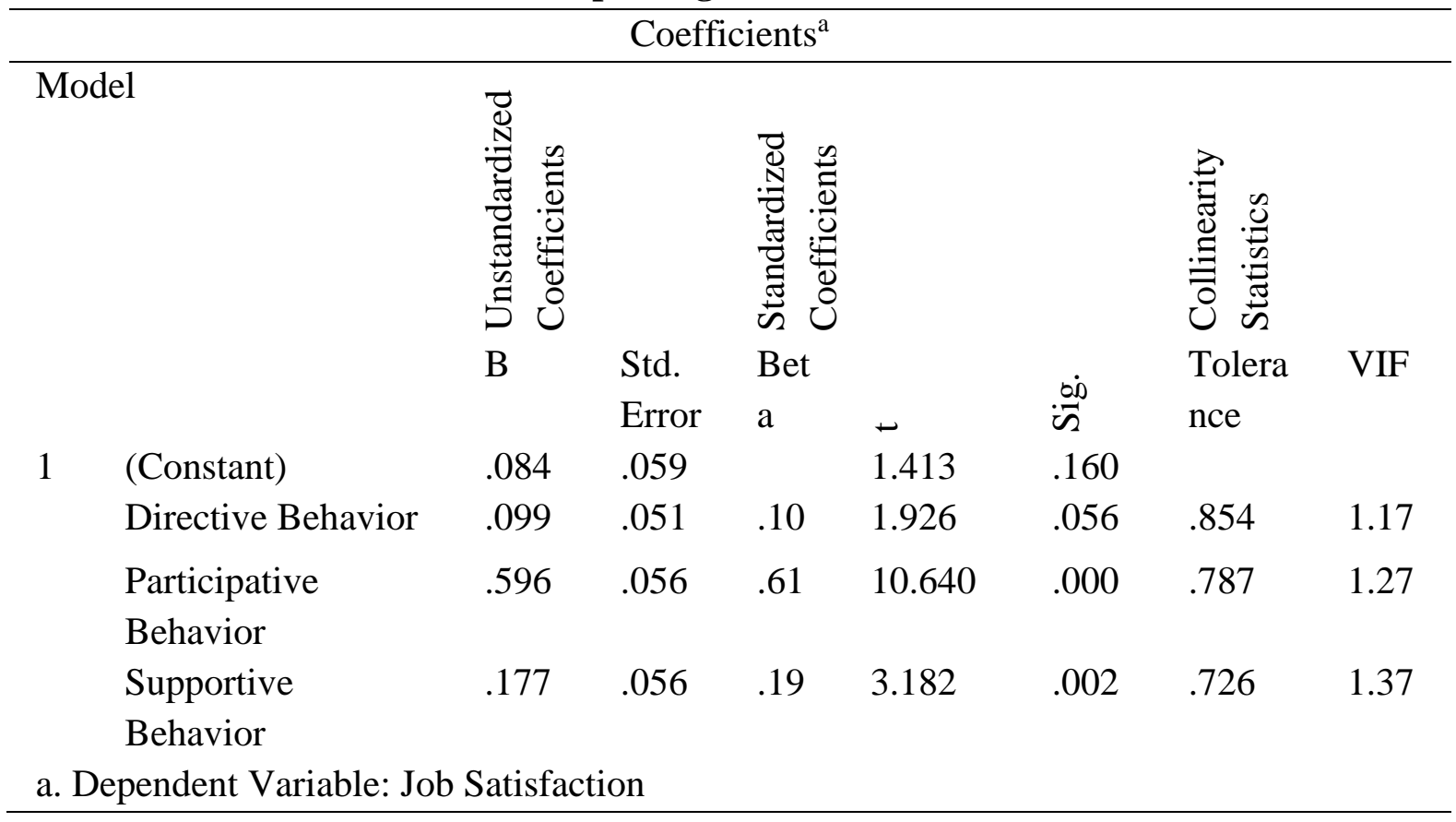

Above table is known as a coefficient it shows the contribution of each variable separately and its significant level in this way here Directive Behavior, Participative Behavior and Supportive Behavior are the independent variables among them directive behavior is contributing $5.6 \%$, participative contributes $61.90 \%$ and supportive contributes $19.30 \%$ further participative and supportive are significant and directive behavior is insignificant one these results supports us whether hypotheses are accepted or rejected even they are helpful to understand objectives and questions here if sig. value is .05 or less than .05 will be treated significant. and beta column shows the contribution whereas, Tolerance must be less than 1 and VIF must be greater than 1 and less than 10 so results shows the accuracy of all .here it is obtained that Micro Finance Banks operating in Khairpur must ensure participative behavior during applying behavior it will encourage 
employees to be satisfied whereas, directive behavior is seen insignificant in Micro Finance Banks. Furthermore, supportive behavior is also favorable for employees in this regard.

\section{Conclusion}

This study diagnosed how different leadership behaviors are responding and influencing on employees job satisfaction in micro finance banks operating in Khairpur District. though leadership in not new theory from many dimensions scholars are diagnosing it and this behavior splits in new ideologies so in this connection directive behavior, Participative and supportive behaviors are main components and all are going to impact on employees job satisfaction in micro finance banks. As, author told this study is confined to Khairpur where limited micro finance banks are working in region only 290 employees are working. Where these employees feel managers have different attitudes and behaviors when they have to impose administrative authority, no doubt they have high pressure from top management to accomplish the organization goals in this regard if their behavior is to determine only participative behavior that can be the behavior that keeps employees to be motivated. if it will not be applied in administration might be control, feedback, daily problems, flexibility and work life balance creates more problems to deal with organizational goals. Let it to be clear that in micro finance banks of Khairpur what results are reflected by data obtained from employees as it was asked from 158 employees to recommend their intention regarding to participative behavior towards employees' job satisfaction. Mostly preferred participative style and in this research participative behavior is contributing $61.90 \%$ and its relationship with employees' job satisfaction is significant so micro finance banks of Khairpur need to create more satisfaction among employees need to pursue participative behavior in dealing with activities to accomplish their organizational tasks and goals. Even (Khan, 2015) suggested that participative behavior is not to work being alone, but it is collective effort of employees to be involved in decision making process. ( Jaffari and Rahim, 2014) participative behavior is associated with employees' job satisfaction. By keeping theses argument in consideration hypothesis was designed however Hypothesis 2: Participative behavior is positively and significantly associated with job satisfaction is proved because its value is very clear in coefficient table and it is positive and significant one namely .619 and .000 even first objective is hence proved to show the contribution of leadership behaviors in predicting employees job satisfaction.

Further this research represents that what is the contribution and association of directive leadership behavior with employees job satisfaction as shown in research objectives, questions and hypothesis so all are reflecting that this style is contributing positively but avoided by employees in micro finance banks of Khairpur because response given by respondents and results indicates that this leadership behavior contributes $10.80 \%$ but it is insignificant. As (Salin \& Helge, 2010) said On the other hand, training is the only way to resolve disputes or resolve disputes. The style of a dictatorship can create an atmosphere of fear, with little or no dialogue, and subordinates believe that the complaint is worthless. In this connection might be employees feel hesitation to work under influence of directive leadership behavior so micro finance banks need to keep it under high consideration if they have need to implement this style might be imposition of it lead high dissatisfaction among employees as results are representing it. So, this Hypothesis 1: Directive behavior is positively and significantly associated with job satisfaction. Is partially supported because it .108 positive but insignificant at .056 
A leader is believed to be a supportive leader when he concerns about subordinate well-being and being supportive to individuals (Malik, 2014) so this leadership behavior is second priority of employees working in micro finance banks of Khairpur and this style contributes 19.30 in this research and also significant because its result is .002 in this regard it is said supportive leadership style is liked by employees if job satisfaction is tried to be created in organization. However, H3: (Supportive behavior of is positively and significantly associated with job satisfaction.) is also supported

Furthermore, this research resents the position of second objective that what is association between directive behavior and participative behavior so there is poor relationship between directive behavior and participative behavior as shown in correlation matrix bearing the value of $.253^{* *}$. It suggests that both styles cannot go on at same time they will lead dissatisfaction among employees.

\section{Conclusion}

This research is concluded that there is significant relationship between leadership behavior and employee job satisfaction according to the references of MFBs of Khairpur district, where almost 14 MF banks are working, through software it stated that if the behavior of leader is not up to the mark it means leader doesn't know properly the behaviors of leader like supportive, directive, and participative then it is tough for a leader to maintain and increase employee job satisfaction,

Further, this study shows leadership behavior is directly proportional to employees' job satisfaction namely Behavior of leader will direct have impacts on employee job satisfaction, as the behavior of leader so the performance and satisfaction of employees.
Further, it is said that organizations need to peruse participative behavior because it influences over employees job satisfaction whereas, directive and supportive behaviors are participating positively but in this study, it is clear, organizations must avoid from directive behavior though its contribution is positive but this will be considered insignificant impact might be due to pressure given by head or leader that you have to do it. Even there is need to carry on this study as diagnose more variables of this study.

\subsection{Recommendations.}

- In this study, the population used for the survey was only limited to fourteen MFBs of Khairpur district where 158 employees became respondents. Therefore, this study can be extended to various other businesses organizations. This will help the researcher to gain an overall understanding of leadership styles and their impact on job satisfaction.

- This research ensures to avoid authoritative leadership behavior in association with employees' job satisfaction.

- Lastly, the future research may consider added measurement instrument for the leadership behaviors relation with job satisfaction to contribute different outcomes through different organization's culture.

\subsection{Implications}

\subsubsection{Theoretical Implications}

It was realized during getting response from employees that they were hesitant to provide response in this research. They were under the control of authority. This annoying behavior made me conscious to provide assurance that this is academic research that will not harm your organization or your policies.

\subsubsection{Managerial Implications}

Numbers of financial organizations are working throughout glob in this regard it is seen 
managerial job in micro finance banks is quite hard and managers are feeling high burden and they try to allow employees achieve set targets of management in this way dissatisfaction arise among the employees. So, managers need to exercise leadership role to keep them satisfied

\subsection{Limitations.}

- This study was confined to specific MFBs of Khairpur district. Because it is difficult to extend research to entire Sindh or Pakistan in a limited resource. It's a purely academic research.

\section{References}

- $\quad$ Khan, M. S., Khan, I., Qureshi, Q. A., Ismail, H. M., Rauf, H., Latif, A., \& Tahir, M. (2015). The styles of leadership: A critical review. Public Policy and Administration Research, 5(3), 87-92.

- Javed, H. A., Jaffari, A. A., \& Rahim, M. (2014). Leadership styles and employees' job satisfaction: A case from the private banking sector of Pakistan. Journal of Asian business strategy, 4(3), 41.

- Djurkovic, N., McCormack, D., Hoel, H., \& Salin, D. (2020). Joking behaviours and bullying from the perspective of Australian human resource professionals. Asia Pacific Journal of Human Resources.

- Malik, S. H., Aziz, S., \& Hassan, H. (2014). Leadership behavior and acceptance of leaders by subordinates: Application of path goal theory in telecom sector. International Journal of Trade, Economics and Finance, 5(2), 170.

- $\quad$ Allen, G. P., Moore, W. M., Moser, L. R., Neill, K. K., Sambamoorthi, U., \& Bell, H. S. (2016). The role of servant leadership and transformational leadership in academic pharmacy. American journal of pharmaceutical education, 80(7).

- Bass, B. M., \& Stogdill, R. (1981). Handbook of leadership. Theory, research, and managerial.

- Garman, A. N., Davis-Lenane, D., \& Corrigan, P. W. (2003). Factor structure of the transformational leadership model in human service teams. Journal of Organizational Behavior: The International Journal of Industrial, Occupational and Organizational Psychology and Behavior, 24(6), 803-812.

- Hartline, M. D., Maxham III, J. G., \& McKee, D. O. (2000). Corridors of influence in the dissemination of customer-oriented strategy to customer contact service employees. Journal of marketing, 64(2), 35-50.

- Hermann, M. G. (2005). Assessing leadership style: A trait analysis. J. Post, 178-212.

- Luu, D. T., \& Phan, H. V. (2020). The effects of transformational leadership and job satisfaction on commitment to organisational change: a threecomponent model extension approach. The South East Asian Journal of Management.

- Mahar, S. A., Soomro, M., Ibupoto, M. H., \& Dahar, S. H. The impact of organizational culture on job satisfaction of the school teacher of city Khairpur Sindh Pakistan.

- Manzoor, F., Wei, L., Nurunnabi, M., Subhan, Q. A., Shah, S. I. A., \& Fallatah, S. (2019). The impact of transformational leadership on job performance and CSR as mediator in SMEs. Sustainability, 11(2), 436.

- Mullins, J., \& Linehan, M. (2005). Leadership and followership in public libraries: transnational perspectives. International Journal of Public Sector Management.

- Naveed Anwar, Q. M. (January 2012). Task Conflict and its Relationship with Employee's Performance. Interdisciplinary Journal of Contemperary Research in Business, 1338-1343.

- Ratnasari, S. L., \& Sutjahjo, G. (2020). The effect of job satisfaction, organizational culture, and leadership on employee performance. Annals of Tropical Medicine and Health, 23, 231-329.

- Riana, I. G. (2015). Effects motivation on business performance: The mediation role of job satisfaction and leadership (a study in village credit institutions). European Journal of Business, Economics and Accountancy, 3(2), 1-11.

- Saxena, N., \& Saxena, D. (2012). Paradigm Change of Leaders, from Transformational Leadership to Super Leadership. Available at SSRN 2528378.

- Selznick, P. (2011). Leadership in administration: A sociological interpretation. Quid Pro Books.

- Spears, L. C., \& Lawrence, M. (Eds.). (2002). Focus on leadership: Servant-leadership for the twenty-first century. John Wiley \& Sons.

- $\quad$ Thornton, K., \& Cherrington, S. (2014). Leadership in professional learning communities. Australasian Journal of Early Childhood, 39(3), 94-102.

- Xue, Y., Li, X., Wang, H., \& Zhang, Q. (2020). How Employee's Leadership Potential Leads to Leadership Ostracism Behavior: The Mediating Role of Envy, and the Moderating Role of Political Skills. International journal of environmental research and public health, 17(9), 3080. 